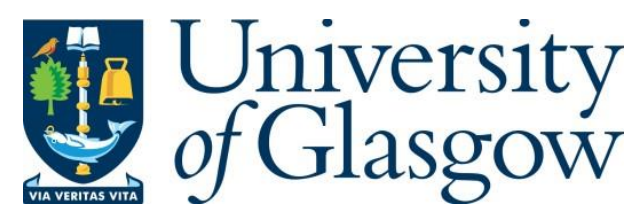

Hunter, D., McCallum, J. and Howes, D. (2018) Compassion in emergency departments. Part 1: nursing students' perspectives. Emergency Nurse, 26(2), pp. 25-30.

There may be differences between this version and the published version. You are advised to consult the publisher's version if you wish to cite from it.

http://eprints.gla.ac.uk/164731/

Deposited on: 21 August 2018

Enlighten - Research publications by members of the University of Glasgow

http://eprints.gla.ac.uk 


\section{Compassion in emergency departments. Part 1: nursing students' perspectives}

Hunter D et al (2017) Compassion in emergency departments. Part 1: nursing students' perspectives. Emergency Nurse.

Date of submission: 30 August 2017; date of acceptance: 30 October 2017. doi: 10.7748/en.2017.e1774

David Hunter

Lecturer in adult health, University of the West of Scotland, Paisley Campus, Renfrewshire, Scotland

Jacqueline McCallum

Assistant head of department, Glasgow Caledonian University, Glasgow, Scotland

Dora Howes

Associate professor, School of Medicine Dentistry and Nursing, University of Glasgow, Glasgow, Scotland

Correspondence

david.hunter@uws.ac.uk

Conflict of interest

None declared

Peer review

This article has been subject to external double-blind review and has been checked for plagiarism using automated software Online

For related information, visit emergencynurse.co.uk and search using the keywords

Write for us

For information about writing for RCNi journals, contact writeforus@rcni.com

For author guidelines, go to rcni.com/writeforus

The authors would like to thank the 15 nursing students who participated in this study.

\section{Abstract}

Compassion is a topical issue in relation to clinical nursing practice, nurse education and policy, but a review of the literature reveals that nursing students' experiences of compassionate care has received little attention. In this three-part series David Hunter and colleagues explore compassion in emergency departments (EDs) from nursing students' point of view. Part one provides results of a PhD study of nursing students' experiences of compassionate care in EDs, part two explores the barriers to compassionate care in this clinical setting that emerged from the study, and part three considers factors that enable and support compassionate care provision in EDs.

Aim: The aim of the study was to explore nursing students' experiences of the provision of compassionate care within EDs.

Method: The underpinning methodology was an exploratory-descriptive qualitative design. 15 nursing students from across the West of Scotland, and who had been placed in eight different EDs, participated in face-to-face interviews which were audio recorded, transcribed, and analysed.

Findings: Two major themes emerged, 'doing the little things' and 'a strange, new world: the uniqueness of the ED'. The students also identified barriers and enablers to providing compassionate care, which are discussed in part two and three.

Conclusion: Despite the challenges of working in the most acute of clinical settings, nurses can provide compassionate care to patients and their relatives. However, this is not universal as certain groups of patients considered 'challenging' do not receive equitable compassionate care. 
compassionate care, emergency department, emergency nurse, exploratory-descriptive qualitative research, student experience

\section{Introduction}

Compassion is at the forefront of healthcare policy and is debated nationally and internationally in the context of practice and education (Dewar 2013). But it is not a new concept in nursing. Florence Nightingale (1860) suggested that nurses should care for patients with empathy and compassion. A number of policy documents that relate to compassionate care have been published in the UK in recent years, including the Willis Commission (2012) on the health of pre-registration nurse education and its future. Compassion is the overriding theme of the report, which draws a number of conclusions, and makes a number of recommendations, including that educating students to degree level does not produce nurses who are less caring or lacking in compassion than their predecessors. The report also highlights concerns about practice-based learning, mentorship and support for newly qualified nurses.

Another significant publication, the Francis Report (2013) , includes a section relating to caring, compassionate and considerate nursing, within which there are a number of recommendations about the recruitment, training and education of nurses, with an increased focus on returning caring and compassion to the core of nursing practice.

Against this background the aim of this study was to explore nursing students' experiences of the provision of compassionate care within emergency departments. Four questions were identified:

1. What does the term 'compassionate care' mean to nursing students?

2. How has nursing students' understanding of compassionate care been developed?

3. Do nursing students learn to deliver compassionate care within EDs, and if so how and from whom?

4. What are the barriers to and enablers of providing compassionate care within EDs, as experienced by nursing students?

\section{Literature review}

Stebbins (2001) suggests that in exploratory research literature reviews are 'carried out to demonstrate that little or no work has been done on the group, process or activity under consideration'. Therefore, in an exploratory-descriptive qualitative (EDQ) study, researchers should search for studies that are most closely related to the topic under investigation, and demonstrate how they leave certain critical aspects of that phenomena unexplored (Stebbins 2001).

A literature search of electronic databases, including CINAHL and MEDLINE, were undertaken as well as Google Scholar. using key words such as 'compassionate care', 'student nurse', 'emergency department' and 'A\&E'. Combinations of these key words, including truncated versions, were used with the Boolean operator 'AND'. A total of 2,409 papers were identified once duplicates were removed, and the main inclusion criteria were papers written in English. Initially the search focused on papers published from 2010 onwards to keep the review up to date, however due to the lack of papers identified older relevant publications were included. A total of 36 publications were considered in the final literature review, the year of publication ranged from 1995 to 2016, although most were published in the past five to six years, and the design and nature of the papers varied (Table 1).

\section{Table 1. Quality of identified papers}

\begin{tabular}{|l|l|}
\hline Research papers & Number of papers \\
\hline Quantitative design & 5 \\
\hline Qualitative design & 12 \\
\hline Mixed-methods design & 1 \\
\hline Literature review & 1 \\
\hline Discussion/continuing professional development papers & 17 \\
\hline
\end{tabular}

The retrieved literature was examined under four categories, what is compassionate care, nursing students and compassionate care, compassionate care and EDs, and nursing students and EDs. Detailed discussion of the literature is outside 
the scope of this article, but there were no studies that explored nursing students' experiences of compassionate care in EDs. Within the context of nursing students and compassionate care, there is literature that considers the recruitment process of students into university. This includes Rankin (2013) who suggested using emotional intelligence testing as part of the recruitment process may help candidates identify if they have the positive values which would enable them to provide compassionate care in clinical practice. Adam and Taylor (2014), meanwhile, suggested it is crucial that pre-registration nurse programmes allow students to develop the skills, knowledge and attitudes required to deliver care with compassion, and that reflective workshops may support this. Adamson and Dewar (2015) suggested that using real life examples of care can help teach students about compassionate care and bridge the known gap between theory and practice. In relation to nursing students in EDs, Hunter (2010) suggested that although they may have pre-placement anxieties, students can integrate into ED teams and develop a range of communication and clinical skills as a result.

\section{Method}

Reid-Searl and Happell (2012) suggested that a qualitative exploratory design allows researchers to explore topics with limited coverage in the literature, and allows participants to contribute to the development of new knowledge. Sandelowski (2000) highlighted that descriptive qualitative studies should be the methodology of choice when the aims of the research are to produce a straightforward description of the phenomenon. This allows researchers to understand who is involved, what was involved and where events took place in relation to the phenomenon of interest (Caelli et al, 2003).

An important point, that Sandelowski (2010) stresses, is that qualitative descriptive studies are not intended to be used to salvage pieces of research that have been poorly conceived or conducted. Qualitative descriptive studies cannot be justified when a different, more interpretive, qualitative methodology would have been more suited to answer the aims of the research. In addition, Stebbins (2001) suggested that exploratory research involves moving beyond description to arriving at an understanding of the phenomena under investigation. While other authors have said they have used an EDQ approach to their research, they have often lacked theoretical underpinning. However, Sehularo et al (2012) stated that 'explorative research examines a phenomenon of interest, rather than simply observing and recording incidents of the phenomenon...' and suggested that the descriptive element is used to gain insight and inform nursing care. Recognising the potential application of Stebbins' (2001) work to nursing, and that of Sandelowski $(2000,2010)$, a hybrid of the two methodologies was created, as illustrated in Figure 1.

\section{Figure 1. The creation of exploratory-descriptive qualitative study (Hunter 2017)}

Ethical approval was granted from the university where the lead author undertook his professional doctorate, and access to the participants was granted from the universities the nursing students attend. Data were collected through individual, face-toface, semi-structured interviews with 15 participants, five first year, five second year, and five third year nursing students from four geographical locations in the West of Scotland. The sample comprised 10 female and five male students. Before recording the interviews, participants chose a pseudonym to enable them to recognise comments they made when the research was published (Duers 2013). Interviews were audio recorded and transcribed verbatim. Thematic data analysis was undertaken based on the work of Braun and Clarke (2006).

\section{Findings}

Two major themes and seven sub-themes emerged from the data following thematic analysis (Figure 2). The main themes were 'doing the little things' and 'a strange, new world: the uniqueness of the ED'. Quotations from the participants are used to illuminate the themes and sub-themes.

\section{Figure 2. Final thematic map following data analysis (Hunter 2017)}

The first theme that emerged was 'doing the little things', and the participants highlighted that compassionate care is about small acts of kindness that hold significance for patients or relatives. Participants suggested that compassionate care takes place during and beyond the physical, often task-oriented elements of care delivery: 'I was surprised at how nice we were. Just 
doing little things like getting air mattresses. Making sure they (patients) were ok with water. Just small things. I knew we would be on things like making sure their obs (observations) were done, making sure that the doctor seen them, all that kind of stuff that you might think as high priority but, em, little touches... I think maybe just going that wee extra bit for somebody, doing something that's maybe a wee bit above and beyond the tick boxes on the front of the admissions sheet, sort of thing, and that would just be whatever was important to the individual you were treating' (Rachel).

When considering how their understanding of compassionate care developed 'evolution through experience', the first subtheme, captured the participants' descriptions. They highlighted that the influence of theory, having a variety of clinical placements and reflecting on their practice all helped them develop as compassionate practitioners: 'I'm still learning just now, everything I'm learning from the university and from previous placements and what I'm doing outwith work as well is also helping with that. (It) is giving me a better understanding of how to look after people' (Thomas).

The second sub-theme was 'communication is the key', and was discussed 24 times by $60 \%(n=9)$ of the participants, which indicates that they saw a clear connection between communication and the delivery of compassionate care. Discussions about this included the use of nonverbal communication, active listening and the ability to build relationships with patients or relatives: 'I think if I was to see compassionate care in other staff members, it's the ones that actually sit down and listen to what the patients have to say... the patient can speak to them about trauma or anything that happened and they can feel like a weight has been lifted. The staff members' not actually said anything, they've just listened, they're a sounding board' (Tom).

The second theme 'a strange, new world: the uniqueness of the ED' relates to the participants' experiences, and how they felt their placements in EDs were completely different from any other settings. Most of the participants ( $n=13)$ described their experience positively: 'I'd only just got used to working in, em, ward settings and places like that, and then to be thrown into A\&E... I was worried I was going to, kind of, sink. That I wasn't going to enjoy it much. However, after the seven weeks, I absolutely loved being there' (Jamie).

Five distinct sub-themes emerged from this that captured the participants' experiences of compassionate care in EDs. The first is 'dealing with death and its consequences'. Just over half $(n=9)$ the participants discussed this element of emergency care and linked it to the main theme of 'doing the little things'. For example, one participant said: 'There was a couple of times when people had come in with cardiac arrests and things and they (the staff) had comforted the family and they had a quiet room and things, you know, I think that is showing, kind of, compassion with concern and, you know, sitting down and making sure they're ok, even offering them a cup of tea and just the way they interact with the, you know, just to show that they cared. So that's part of compassion, for me anyway, I think that's an instance I can... that showed that' (Robert).

Although this is a difficult element of nursing practice (Lawrence 2010), the participants who discussed dealing with death and caring for the bereaved in an ED were overwhelmingly positive about their experience, and suggested it was transferable to other settings.

The second sub-theme 'challenging patient encounters' relates to three patient groups and situations that participants had experienced in EDs, and which influenced the delivery of compassionate care. These were patients who attended with an alcohol- or drug-related issue, those with mental health problems or who were aggressive, and those who attended an ED regularly: 'I think some kind of comments made about mental health patients, or patients who come in drunk or overdoses: "oh, it's the, it's the repeat offender"' (Ellie).

The third sub theme, 'physicality of the department', had both positive and negative connotations when it came to the delivery of compassionate care. On a positive note, participants described how a benefit of working in the resuscitation area was the ability to provide more one-to-one nursing care, which in turn improved their compassionate care delivery. In addition, they suggested that, at times, the nurses working in the resuscitation area had more time to spend with patients than those in other areas of the department. In contrast, other areas of the department, in which space was limited and there were issues with equipment, had a negative effect on compassionate care. One participants commented: 'People on corridors and moving people out to move people in to get assessed and then back out. That's just horrendous. I would hate to be sick there, lying in a corridor where people can walk by and see that, and it's sick the way... writhing about in pain or vomiting and, or having bits exposed because you're moving about that don't need to be and I think that's just, it's not very pleasant' (Ellie). 
The fourth sub-theme was the influence of 'time and government targets'. 14 of the 15 participants discussed this and regarded it as having a negative influence on compassionate care. Participants linked the amount of time available to build relationships with their patients to delivery of compassionate care. The government four-hour waiting target was discussed, and one participants described the movement of patients as 'bed Tetris'. Although predominately seen as a negative aspect, some participants recognised that they had developed skills in building relationships with patients and families quickly, and that they could take this with them to their future practice: 'Staff members said I was great with patients but I just feel sometimes it was very much, a very shallow relationship. It was almost like speed dating, except with patients' (Tom).

The final sub-theme was the 'support mechanisms' available to students in EDs. The participants recognised that they had been well supported during their placements, made positive comments about teamwork and how it enhances compassionate care, and commented on staff as role models. This was mainly a positive discussion, but participants recognised that negative aspects could still be a positive learning experience. Some participants commented on staffing levels and suggested that low levels affected their learning and the delivery of compassionate care.

Finally, some of the participants suggested the need for mental health nurses or support workers to be based in the ED to support patients with mental health presentations.

\section{Discussion}

The discussion mainly focuses on the first three research questions. The fourth question, relating to barriers and enablers of compassionate care in EDs, is discussed in part 2 and part 3 of this series.

Participants described how compassionate care was about 'doing the little things' and recognised that small acts of kindness can have a significant effect on the quality of care. Pearson (2006) said that these 'little things' are 'known to be important, but have little status. They are seen as simple, not clever; basic, not exquisite; peripheral, not central'.

The participants suggested there were many circumstances in which they could demonstrate compassion while performing aspects of nursing care, and highlighted that providing compassionate care did not depend on their stage of education.

Dewar et al (2011) identified that many acts of compassionate care occur during routine acts of nursing. However, nurses may have difficulty discussing these or their significance to patients, as they may feel embarrassed or perceive themselves as boasting (Dewar et al 2009), Dewar and Mackay 2010). In addition, the participants commented that communication and building relationships with patients and their families were important elements of visible compassionate care.

Participants described how their understanding of compassionate care had developed during their programme through different mechanisms. First, the influence of theory, including materials taught directly in university and Nursing and Midwifery Council guidelines, such as those set out in the Code (2017). This supports Richardson et al (2015) who found that compassion can be taught. Second, the participants recognised that the variety of practice learning experiences influenced their understanding of compassionate care, and that encounters with a range of patient groups developed their ability to provide it. Curtis et al (2012) highlighted that nursing students are expected to develop their understanding of compassionate care from nursing theory and through exposure in practice. A variety of practice learning experiences exposes students to wider experiences of patient journeys, thus helping them develop a patient-centred approach to care (Millar 2014).

In addition, the participants discussed how reflecting on their clinical experiences helped them consider their practice in relation to delivering compassionate care and how it could be enhanced. Nursing students are advised that reflection can help improve patient care by developing their skills, expanding their knowledge base, examining their behaviours and interactions with others and making sense of difficult or challenging situations (Thorpe et al 2015). Finally, and specifically relating to EDs, participants described their experiences of caring for the dead, dying and bereaved, which had a significant effect on their understanding of how high quality compassionate care can be provided to this patient group. This is explored in more detail in part 3.

Two main factors were identified from responses to the question if, how and from whom nursing students learn to deliver compassionate care in EDs. The participants described the beneficial aspects of being in a supportive learning environment, mirroring Hunter (2010) and Henderson et al's (2009) work, which recognised that the quality of everyday interactions with clinical staff has a direct effect on the quality of students' clinical experiences and subsequent learning. Participants described 
EDs in which learning was encouraged, team work/dynamics were strong, and they witnessed staff showing compassion to one another. Additionally, participants recognised the significance of staff as role models on their development of compassionate care delivery in this clinical environment. When students are exposed to the behaviours of registered nurses they consider either positive or negative role models, this has an influence on their professional development (Keeling and Templeman 2013).

\section{Limitations}

The findings are based on interviews with 15 nursing students studying at the same university, and had been exposed to the same theoretical content, therefore nursing students from other universities, or in different geographical areas, could give different responses. The study involved nursing students undertaking a BSc Adult Nursing degree, and it is possible that those in other fields of nursing could have a different perspective of what compassionate care means to them or how it occurs in EDs.

\section{Conclusion}

The students in this study described how EDs were completely alien compared to their other practice learning experiences. Despite the challenges of working in the most acute of clinical settings, nurses can provide compassionate care to patients and their relatives. However, it is not universal. Students described certain patients who perhaps do not receive the compassionate care that they should and identified this as a barrier to its provision. However, they also recognised that there are opportunities to overcome these barriers, and these are discussed in parts two and three. Students were overwhelmingly positive about their experiences in EDs and the beneficial effects of these on their future nursing practice.

\section{References}

Adam D, Taylor R (2014) Compassionate care: empowering students through nurse education. Nurse Education Today. 34, 9, $1242-1245$.

Adamson E, Dewar B (2015) Compassionate care: student nurses' learning through reflection and the use of story. Nurse Education in Practice. $15,3,155-161$.

Allen M, Allison MM, Stevens S (2006) Mapping the literature of nursing education. Journal of the Medical Library Association. 94, 2, E122E127.

Braun V, Clarke V (2006) Using thematic analysis in psychology. Qualitative Research in Psychology. 3, 2, 77-101.

Curtis K, Horton K, Smith P (2012) Student nurse socialisation in compassionate practice: a grounded theory study. Nurse Education Today. 32 , 7, 790-795.

Dewar B, Mackay R (2010) Appreciating and developing compassionate care in an acute hospital setting caring for older people. International Journal of Older People Nursing. 5, 4, 299-308.

Dewar B, Mackay R, Smith S et al (2009) Use of emotional touch points as a method of tapping into the experience of receiving compassionate care in a hospital setting. Journal of Research in Nursing. 15, 1, 29-41.

Dewar B, Pullin S, Tocher R (2011) Valuing compassion through definition and measurement. Nursing Management. 17, 9, 32-37.

Dewar B (2013) Cultivating compassionate care. Nursing Standard. 27, 34, 48-55.

Duers L (2013) 'To See Oursels as Ithers See Us!' An Exploration of Student Nurses' Conceptions and Implementation of Peer Review and Selfassessment. EdD Thesis, University of Strathclyde.

Francis R (2013) Report of the Mid Staffordshire NHS Foundation Trust Public Inquiry, The Stationary Office, London.

Henderson A, Twentyman M, Eaton E et al (2009) Creating supportive clinical learning environments: an intervention study. Journal of Clinical Nursing. 19, 1/2,177-182.

Hunter D (2010) How clinical practice placements affect professional development. Emergency Nurse. 18, 5, 30-34.

Hunter D (2017) A strange, New World: Compassion in the Emergency Department as Experienced by Student Nurses. An ExploratoryDescriptive Qualitative Study. ProfD Thesis, Glasgow Caledonian University.

Keeling J, Templeman J (2013) An exploratory study: student nurses' perceptions of professionalism. Nurse Education in Practice. 13, 1, $18-22$. Lawrence N (2010) Care of bereaved parents after sudden infant death. Emergency Nurse. 18, 3, 22-25.

Millar L (2014) Use of hub and spoke model in nursing students' practice learning. Nursing Standard. 28, 49, 37-42.

Nightingale F (1860) Notes on Nursing: what It Is and What It Is Not. Harrison and Sons, London.

Pearson A (2006) Powerful caring. Nursing Standard. 20, 48, 20-22.

Rankin B (2013) Emotional intelligence: enhancing values-based practice and compassionate care in nursing. Journal of Advanced Nursing. 69, $12,2717-2725$. 
Richardson C, Percy M, Hughes J (2015) Nursing therapeutics: teaching student nurses care, compassion and empathy. Nurse Education Today. 35, 5, e1-e5.

Sandelowski M (2000) Whatever happened to qualitative description? Research in Nursing and Health. 23, 4, 334-340.

Sandelowski M (2010) What's in a name? Qualitative description revisited. Research in Nursing and Health. 33, 1, 77-84.

Stebbins RA (2001) Exploratory Research in the Social Sciences. Sage Publications, London.

Thorpe G, Mason J, Delves-Yates C (2015) Core academic skills. In Delves-Yates C (Ed) Essentials of Nursing Practice. Sage Publications Ltd, London: 29-45.

Willis Commission, (2012) Quality with Compassion: The Future of Nursing Education. Report of the Willis Commission on Nursing Education. Royal College of Nursing, London. 